\title{
Investigation of Air Pollution from Automobiles at Intersections on Some Selected Major Roads in Ogbomoso, South Western, Nigeria
}

\author{
O.O. S. Ojo ${ }^{1}$ and O.S. Awokola ${ }^{2}$ \\ ${ }^{1}$ Department of Civil Engineering, University of Ibadan, Oyo State, Nigeria \\ ${ }^{2}$ Department of Civil Engineering, Federal University of Agriculture, Abeokuta, Ogun State Nigeria.
}

\begin{abstract}
This paper reports the results of the investigation of air pollution from automobiles at intersections on some selected major roads in Ogbomoso, South Western, Nigeria. Four sampling routes were considered with ten sampling points $(\mathrm{SP} 1-\mathrm{SP} 10)$ placed $2.0 \mathrm{~m}$ away from the edge of the road. Priority parameters: $\mathrm{SO}_{2}$, $\mathrm{NO}_{x}$, CO were monitored. The results of $\mathrm{SO}_{2}, \mathrm{NO}_{x}, \mathrm{CO}$ were in the range of $0.02-0.09 \mathrm{ppm}, 0.009-0.039 \mathrm{ppm}$, 1.79-51.38ppm respectively. The concentration of $\mathrm{SO}_{2}$ was highest at $\mathrm{SP} 6$ with value 0.5103ppm. Emission concentration for $N_{x}$ was found to be highest at SP 6 where traffic congestion and traffic intersection is observed. The highest level obtained for the air pollution indicator of CO was at: SP 9, 6, 3and 10 due to traffic congestion and traffic intersection, where long waiting time for vehicles was observed. All the three monitored air pollutants when compared with AQI level (Air quality index) were in the range of: $\mathrm{SO}_{2}$ - was from very poor to good, $\mathrm{NO}_{x^{-}}$from good to very good, $\mathrm{CO}$ - very good to moderate and moderate to poor in different locations. The study concludes that, it has become quite important to understand the role of mobile source emissions on air quality through well-designed studies. This information can provide important input for the formulation of effective air quality management strategies.
\end{abstract}

\section{Introduction}

Air is a universal gas, without which existence of humans and other forms of life is possible. Air quality is very essential to sustain life. Air pollution due to human activities is an abuse to the environment thereby degrading the air quality. Air pollutants associated with traffic-related emissions such as nitrogen oxides $\left(\mathrm{NO}_{\mathrm{x}}\right)$, carbon monoxide $(\mathrm{CO})$ and particulates $\left(\mathrm{PM}_{10}\right)$ have been recognized to have significant impact on human health with evidence suggesting causal associations between elevated $\mathrm{PM}_{10}$ and mortality, due to air pollution problem has been well documented in Europe and United States with motor vehicles being the main contributors. In UK the average concentration of $\mathrm{NO}_{2}$ was found to increase by $35 \%$ from 1986 to 1991 due to increase in vehicular emission CEC, (1992).

In specific studies relating to the Nigerian experience, attention has been focused more on general industrial pollution or pollution in the oil industry (Faboya, 1997; Iyoha, 2000; Magbagbeola, 2001, and Orubu et al., 2002), while in other studies, only casual references are made to the gravity of the problem of pollution from mobile transportation sources (World Bank, 1995; Garba and Garba, 2001).

Vehicular pollution arises mainly from inefficient combustion of hydrocarbon fuels. Hydrocarbon gases easily unite with oxides of nitrogen (NOx) through photochemical reactions in sunlight to produce smog. NOx can combine with other organic substances in the atmosphere to create ozone, with devastating effects on vegetation and climatic stability. Hydrocarbon fuels also contain varying amounts of sulphur. The combustion of hydrocarbon (HC) fuels therefore has the potential of producing oxides of sulphur, which can combine with water in the atmosphere to form acids of sulphur. Carbon monoxide (CO), produced as a result of inefficient combustion of hydrocarbon fuels and is highly toxic even at small levels of concentration, and has been known to decrease human efficiency. In effect, cities, which rely on a large number of vehicles for the bulk of daily commuting transportation, and offering few efficient public mass transportation modes, may suffer from extreme $\mathrm{CO}$ and other transportation-related emissions.

Today, mobile source emissions have tended to be the largest contributor to urban emission inventories in many locations.

There has been no legislative framework for air quality in Nigeria prior to 1988 due to constant long history of military dictatorship. After the discovery of an Italian ship in May 1988 of some imported toxic chemical wastes, discussions geared towards more environmental legislation. Federal Military Government under Decree 58 of 30 December 1988 established the Federal Environmental Protection Agency with statutory responsibility for overall protection of the environment and setting and enforcing ambient and emission standards for air, water and noise pollution. The Environmental Impact Assessment reaffirmed the powers of the FEPA and defined the minimum requirements for an EIA. A study of the impacts of urban road transportation 
on the ambient air was conducted by Koku and Osuntogun, (2007) in three cities of Nigeria: Lagos, Ibadan and Ado - Ekiti all in South-west region of Nigeria.

In Lagos, air quality indicators namely $\mathrm{CO}, \mathrm{SO}_{2}, \mathrm{NO}_{2}$, and total suspended particulates (TSP) were determined. The highest levels obtained for the air pollution indicators were $\mathrm{CO}-233 \mathrm{ppm}$ at Idumota, $\mathrm{SO}_{2}$ $2.9 \mathrm{ppm}$ at Idumota, $\mathrm{NO}_{2}-1.5 \mathrm{ppm}$ at Iyana-Ipaja and total particulates $852 \mathrm{cpm}$ at Oshodi bustop. At Ibadan, the $\mathrm{CO}$ and $\mathrm{SO}_{2}$ levels at 271 and $1.44 \mathrm{ppm}$ were highest at Mokola round about while $\mathrm{NO}_{2}$, at $1.0 \mathrm{ppm}$ was highest at Bere round about. In Ado-Ekiti the highest level obtained were $\mathrm{CO}-317 \mathrm{ppm}$ at Oke Isha, $\mathrm{NO}_{2}-0.6 \mathrm{ppm}$ at Ijigbo Junction and $\mathrm{SO}_{2}-0.8 \mathrm{ppm}$ at Old Garage Junction. The obtained results of $\mathrm{CO}, \mathrm{SO}_{2}, \mathrm{NO}_{2}$, and particulate were found to be higher than FEPA limits (FEPA Limits are $\mathrm{CO}-10 \mathrm{ppm}, \mathrm{SO}_{2}-0.01 \mathrm{ppm}, \mathrm{NO}_{2}-0.04$ to $0.06 \mathrm{ppm}$. The noise level in all the locations were found to be higher than FEPA limit of 90dB and the WHO limit of $70 \mathrm{~dB}-75 \mathrm{~dB}$ (WHO, 2000). Conclusions of this investigation show a growing risk of traffic-related problems in Nigeria cities and demand for serious air quality measures. Orubu, (2001) stated that comparative figures of Lagos and the Niger Delta area can be used to make some deductions on the intensity of pollution from automobile sources in different cities and zones in Nigeria. Lagos, Nigeria's former capital city has a population of about 14 million people, and remains the largest urban commercial and industrial centre in the country, on the other hand, Port-Harcourt and Warri are two major cities in the Niger Delta area with fairly large populations and industrial establishments.

A similar study of the investigation of vehicular emissions in selected areas in Calabar, Nigeria (Abam and Unachukwu, 2009), indicated that the results of $\mathrm{CO}, \mathrm{NO}_{2}, \mathrm{SO}_{2}, \mathrm{PM}_{10}$ and noise level were in the range of 3.3-8.7ppm, $0.02-0.09 \mathrm{ppm}, 0.04-0.15 \mathrm{ppm}, 170-260 \mu \mathrm{g} / \mathrm{m} 3$ and $58.5-72.4 \mathrm{~dB}$ respectively. Using the United State Environmental Protection Agency (USEPA) Air Quality Index level (AQI) Table 1. All the five monitored air pollutants when compared with Air Quality Index level (AQI) Table 1.

Table 1: Air quality index for priority pollutants

\begin{tabular}{lccccc}
\hline \multicolumn{1}{c}{ AQI Category } & $\begin{array}{c}\text { AQI } \\
\text { rating }\end{array}$ & $\begin{array}{c}\text { PM10 } \boldsymbol{\mu} \\
\mathbf{g} / \mathbf{m 3}\end{array}$ & $\begin{array}{c}\text { CO } \\
(\mathbf{p p m})\end{array}$ & $\begin{array}{c}\text { NO2 } \\
(\mathbf{p p m})\end{array}$ & SO2 (ppm) \\
\hline Very good $(0-15)$ & $\mathrm{A}$ & $0-15$ & $0-2$ & $0-0.02$ & $0-0.02$ \\
Good $(16-31)$ & $\mathrm{B}$ & $51-75$ & $2.1-4.0$ & $0.02-0.03$ & $0.02-0.03$ \\
Moderate $(32-49)$ & $\mathrm{C}$ & $76-100$ & $4.1-6.0$ & $0.03-0.04$ & $0.03-0.04$ \\
Poor $(50-99)$ & $\mathrm{D}$ & $101-150$ & $6.1-9.0$ & $0.04-0.06$ & $0.03-0.04$ \\
Very Poor $(100$ or & & & & & \\
over) & $\mathrm{E}$ & $>150$ & $>9.0$ & $>0.06$ & $>0.06$ \\
\hline
\end{tabular}

Source: USEPA 2000

The results were in the range of: $\mathrm{CO}$ - poor to moderate and moderate to poor in different locations. $\mathrm{SO}_{2}$ - was from very poor to poor, $\mathrm{NO}_{2}$ - from very poor to poor, $\mathrm{PM}_{10}$ and noise level was poor at all locations. The overall comparison of data shows that the concentration of pollutants is high due to the volume of traffic and pollution.

The overall levels of vehicular related air pollution in Nigeria from all the studies conducted show an increasing trend and indeed significant with possible severe health consequences.

It is not out of place to state that the concentration of these pollutants must have increased tremendously in the past ten years of democratic rule in Nigeria due to the influx of old and fairly used vehicles into the country following changes in government policy.Over 60 percent of all activities are carried out using motor vehicles supported greatly by the use of two-stroke engine motor-cycles ("okada") for public transport throughout our cities. At least half a million motor-cycles ply the nooks and crannies of our cities. The problem has been exacerbated by the relatively high numbers of old and poorly maintained vehicles, which were imported into the country as fairly used cars popularly known as "tokunbo cars".

The impact and complexity of traffic-related air pollution in Nigeria today, alongside concurrent emissions from industrial and domestic sources therefore necessitates a new approach to the mitigation and management of air pollution. An assessment of the potential for increased vehicular pollution requires some basic information relating to traffic volume and the intensity of pollutant emissions on road corridors. This research work is intended to investigate the level of vehicular emission and air quality standard in Ogbomoso, South Western Nigeria. The knowledge from this investigation will assist appropriate authorities in planning adequate pollution control measures. It is equally hoped that the study will generate interest on further research on the impact of vehicle emission on air quality and health implications in Nigeria in general for effective air quality control and management.

\section{The Study Area}

Ogbomoso is situated in South-Western Nigeria ( $4^{\circ} 16^{\prime} 0^{\prime \prime}$ East; $8^{\circ} 8^{\prime} 0^{\prime \prime}$ North). It has two distinct seasons; dry (October - March) and wet (April - September). Temperature ranges are small and constant throughout the year. It's hottest month records $28^{\circ} \mathrm{C}\left(82.4^{\circ} \mathrm{F}\right)$ and its coolest month $26^{\circ} \mathrm{C}\left(78.8^{\circ} \mathrm{F}\right)$ with the 
temperature range of not more than $2{ }^{\circ} \mathrm{C}\left(5^{\circ} \mathrm{F}\right)$. Being located along Ibadan - Oyo - Ilorin route, Ogbomoso has witnessed positive growth in road traffic.

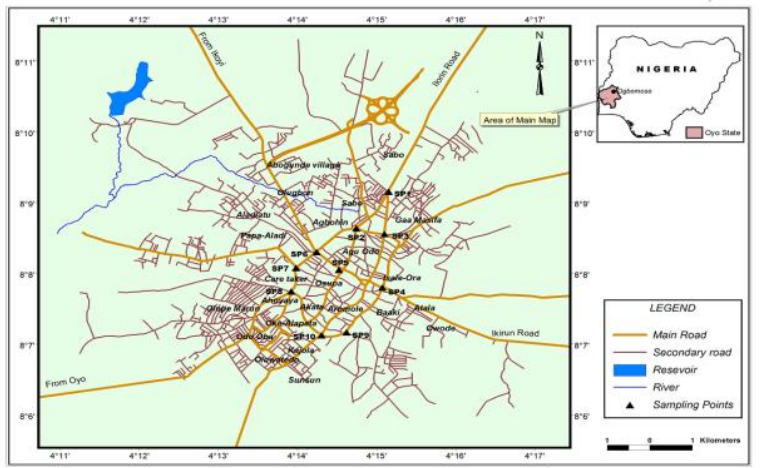

Figure 1: Map of Study area, indicating the sampling points

\section{Materials and Methods}

Major roads along Ogbomoso North and South Local Government areas were considered due to high traffic volume always experienced on this roads and the location of commercial activities along these roads. Four sampling routes were considered with ten sampling points (SP1 - SP10) placed 2.0m away from the edge of the road. In addition, slow movement of vehicles at some locations along these roads was a considerable factor in the collection of air samples so as to determine the concentration of the pollutants being inhaled by the pedestrians and residents of the vicinity. The sampling routes, points and locations are as shown in Table 2 below.

\begin{tabular}{|c|c|c|c|c|}
\hline S/NO & Sampling Routes & $\begin{array}{l}\text { Sampling } \\
\text { points }\end{array}$ & GPS & Sampling locations \\
\hline \multirow[t]{2}{*}{1} & $\begin{array}{l}\text { General Hospital - } \\
\text { Starlight }\end{array}$ & SP 1 & 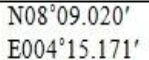 & General Junction \\
\hline & & SP 2 & $\begin{array}{l}\text { N08 }{ }^{\circ} 08.500^{\prime} \\
\text { E004 }^{\circ} 14.762^{\prime}\end{array}$ & Starlight Junction \\
\hline \multirow[t]{3}{*}{2} & Orita Naira - Isale Ora & SP 3 & $\begin{array}{l}\text { N08 } 08.422^{\prime} \\
\text { E004 } 15.117^{\prime}\end{array}$ & Orita Naira Junction \\
\hline & & SP 4 & 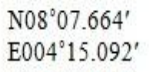 & Isale Ora Junction \\
\hline & & SP 5 & $\begin{array}{l}\text { N08 }{ }^{\circ} 07.916^{\prime} \\
\text { E004 }^{\circ} 14.608^{\prime}\end{array}$ & Oke-Elerin Junction \\
\hline \multirow[t]{3}{*}{3} & Takie - Caretaker & SP 6 & $\begin{array}{l}\text { N08 }{ }^{\circ} 08.167^{\prime} \\
\text { E}^{\prime}\end{array}$ & Takie Junction \\
\hline & & SP 7 & 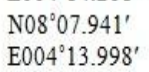 & Seminary Junction \\
\hline & & SP 8 & $\begin{array}{l}\text { N08 } 8^{\circ} 07.609^{\prime} \\
\text { E}^{\prime} 04^{\circ} 13.940^{\prime}\end{array}$ & Caretaker Junction \\
\hline \multirow[t]{2}{*}{4} & $\begin{array}{l}\text { Ora'gada - } \\
\text { Arowomole }\end{array}$ & SP 9 & $\begin{array}{l}\text { N08 }{ }^{\circ} 07.032^{\prime} \\
\text { E004 }^{\circ} 14.637^{\prime}\end{array}$ & Ora'gada Junction \\
\hline & & SP 10 & $\begin{array}{l}\text { N08 } 06.991^{\prime} \\
\text { E004 } \\
14.324^{\prime}\end{array}$ & Arowomole Junction \\
\hline
\end{tabular}

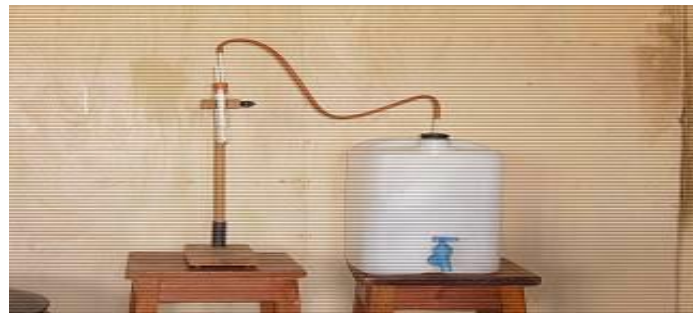

Figure 2: A Simple Air Sampling Apparatus

The aspirator bottle contained clean water with an outlet (valve) at the bottom. It has a drilled rubber cork at its top through which a glass tube siphons air from the atmosphere into the aspirator through a Teflon tube. The Teflon tube is connected to a boiling tube containing absorbent (absorbing reagent) depending on the type of pollutant intended to be investigated. The boiling tube mounted on a retort stand carried a rubber cork with two glass tubes. The first glass tube was connected to the Teflon tube while the second had its end exposed through which air was passed into the boiling tube. 


\section{Experimental Procedure}

The aspirator bottle was filled with water up to the upper limit with the cork in place. As the valve at the bottom of the aspirator was opened, a partial vacuum was created in the aspirator thus forcing air to flow into the aspirator through the Teflon tube connecting both the boiling tube and aspirator. This was as a result of air bubbled into the absorbent through the exposed glass tube while the excess air in the boiling tube was passed to the aspirator to offset the partial vacuum created by the running water. A constant flow rate was maintained so as to ensure that the absorbent absorbed the needed pollutants from air effectively. Priority parameters: $\mathrm{CO}$, $\mathrm{NO}_{x}, \mathrm{SO}_{2}$ were monitored. These pollutants were collected using different absorbing reagents Hydrogen Peroxide for $\mathrm{SO}_{2}$, Sodium Nitrite for $\mathrm{NO}_{x}$, Distilled water for $\mathrm{CO}$. The duration of sampling at individual sampling points was 5 days on a 12 hours basis. The $\mathrm{CO}, \mathrm{SO}_{2}$ and $\mathrm{NO}_{\mathrm{x}}$ were determined using standard method in compliance with USEPA method. The results of the mean values of ambient air measurement in Ogbomoso obtained are tabulated in Table 3. Using USEPA AQI for the mean values obtained for the different mean values of $\mathrm{SO}_{2}, \mathrm{NO}_{2}, \mathrm{NO}$ and $\mathrm{CO}$ the results are as shown in Table 4

Table 3: Results of Mean Values of Ambient Air Measurement in Ogbomoso

\begin{tabular}{cclcccr} 
& & & \multicolumn{5}{c}{ Mean Values (ppm) } \\
\hline & $\begin{array}{c}\text { Sampling } \\
\text { points }\end{array}$ & Sampling Locations & SO $_{2}$ & NO $_{2}$ & NO & CO \\
\hline General Hospital - Starlight & SP 1 & General Junction & 0.0609 & 0.025 & 0.016 & 1.79 \\
& SP 2 & Starlight Junction & 0.0439 & 0.028 & 0.018 & 2.23 \\
Orita Naira - Isale Ora & SP 3 & Orita Naira Junction & 0.0504 & 0.013 & 0.009 & 16.98 \\
& SP 4 & Isale Ora Junction & 0.0278 & 0.027 & 0.017 & 4.92 \\
& SP 5 & Oke-Elerin Junction & 0.0251 & 0.027 & 0.018 & 7.59 \\
Takie - Caretaker & SP 6 & Takie Junction & 0.5103 & 0.039 & 0.025 & 17.87 \\
& SP 7 & Seminary Junction & 0.0126 & 0.017 & 0.011 & 4.47 \\
& SP 8 & Caretaker Junction & 0.0323 & 0.026 & 0.017 & 3.02 \\
Ora'gada - Arowomole & SP 9 & Ora'gada Junction & 0.0493 & 0.025 & 0.016 & 51.38 \\
& SP 10 & Arowomole Junction & 0.0126 & 0.029 & 0.019 & 14.29 \\
\hline
\end{tabular}

Table 4: Results of AQI rating for ambient air quality from study

\begin{tabular}{lccccc}
\hline & Sampling & \multicolumn{4}{c}{ AQI } \\
\cline { 3 - 6 } \multicolumn{1}{c}{ Sampling Routes } & points & SO $_{2}$ & NO $_{2}$ & NO & CO \\
\hline General Hospital - & & & & & \\
Starlight & SP 1 & E & B & A & A \\
Orita Naira - Isale Ora & SP 2 & C & B & A & B \\
& SP 3 & E & A & A & E \\
Takie - Caretaker & SP 4 & B & B & A & C \\
& SP 5 & B & B & A & D \\
Ora'gada - Arowomole & SP 6 & E & C & B & E \\
& SP 7 & A & A & A & C \\
& SP 8 & C & B & A & B \\
& SP 9 & E & B & A & E \\
\hline
\end{tabular}

\section{Results And Discussion}

It was observed from Table 3, that sampling point SP 6 had the highest level of $\mathrm{SO}_{2}$ concentration, the least level of this pollutant were observed at sampling points SP 7 and SP 10. The concentration of $\mathrm{SO}_{2}$ was found in the range of $0.0126-0.5103 \mathrm{ppm}$, at some locations the emission values were within the limit of USEPA ambient air quality standards, while at other locations they were above the USEPA limits. The concentration of $\mathrm{NO}_{\mathrm{x}}$ was found in the range of 0.009-0.039ppm, the highest value was found at SP 6. The reason for this high value could be due to traffic congestion and traffic intersection, where long waiting time for vehicles is observed. The $\mathrm{NO}_{2}$ concentration at all the stations was within the boundary of USEPA ambient air quality standards. The reason could be low traffic level which may transfer pollutants away from station point of high concentration. In terms of AQI rating, the air quality for $\mathrm{NO}_{\mathrm{x}}$ at all the locations is from moderate to very good. The results of $\mathrm{CO}$ were in the range of $1.79-51.38 \mathrm{ppm}$ which was above the permissible limit of USEPA ambient air quality standards. Comparing the values of $\mathrm{CO}$, the highest values are seen at SP 9, 6, 3and 10 due 
to traffic congestion and traffic intersection, where long waiting time for vehicles was observed. In terms of Air Quality Index (AQI) as in Table 4, the CO varies from E to D (very poor to poor) at SP 10, SP 9, SP 6and SP 3, $\mathrm{C}$ to $\mathrm{D}$ (moderate to poor) at SP 4, SP 5and SP 7 while three locations are at A to B (good to very good). The $\mathrm{AQI}$ level (Air quality index) of $\mathrm{SO}_{2}$ were in the range - very poor to good, $\mathrm{NO}_{\mathrm{x}}$ - from good to very good in different locations. The limit set by the Federal Ministry of Environment, Nigeria are Carbon monoxide $10 \mathrm{ppm}$, Sulphur dioxide 0.01 ppm, Nitrogen dioxide 0.04-0.6 ppm (Anonymous, 1991). The mean concentration of CO, $\mathrm{SO}_{2}, \mathrm{NO}_{\mathrm{x}}$ pollutants were found to be much higher when compared with the Federal Ministry of Environment limit. The mean concentration of CO obtained when compared with the results obtained for heavy traffic points in Lagos, Ibadan and Ado Ekiti (Koku and Osuntogun, 2007) were much lower. Mobile source emissions would continue to be the largest contributor to the urban emission inventories. The numerous benefits of motor vehicles transportation would also continue to be offset partially by the air pollution generated by motor vehicles with the attendant health risk and hazards. Consequently, it has become quite important to understand the role of mobile source emissions on air quality through well-designed studies. This information can provide important input for the formulation of effective air quality management strategies.

\section{References}

[1]. Abam F. I. and Unachukwu G. O. 2009: "Vehicular Emissions and Air Quality Standards in Nigeria". European Journal of Scientific Research Vol.34 No.4 (2009), pp.550-560.

[2]. CEC, 1992: The state of the environment in the European Community. Overview, Vol. 3.Commission ofthe Communities, Brussels and Belgium.

[3]. Faboya, O.O., 1997: "Industrial pollution and waste management" pp 26-35 in AkinjideOsuntokun(Ed), Dimensions of Environmental problems in Nigeria, Ibadan Davidson press.

[4]. Federal Environmental Protection Agency (1991): "National Interim Guidelines and Standardsfor Industrial Effluents, Gaseous Emissions and Hazardous Wastes." Environmental Pollution Control Handbook, FEPA, Lagos pp 62 - 67.

[5]. FGN (1988): Federal Environmental Protection Agency Decree 58, 1988, Federal Ministry of Information and Culture, Lagos, Nigeria.

[6]. FGN (1992): Environmental Impact Assessment Decree № 86 of 1992, Federal Ministry of Information and Culture, Lagos, Nigeria.

[7]. Garba, A.G. and Garba P.K.. 2001: "Market Failure and Air Pollution in Nigeria: A theoretical Investigation of Two Cases", Selected papers, Annual Conference Nigerian Economic Society, held at Port-Harcourt.

[8]. Iyoha, M. A., 2009: The Environmental effects of oil industry activities on the Nigerian Economy:A theoretical Analysis: Paper presented at National Conference on the management of Nigeria's petroleum Resources, organised by the Department of Economics, Delta State University.

[9]. Jerome, A. 2000: "Use of Economic instruments for Environmental Management in Nigeria" Paper presented at a workshop on Environmental Management in Nigeria and Administration (NCEMA).

[10]. Koku, C.A., Osuntogun, B.A. 2007: Enviromental-Impacts of Road Transportation in Southwestern States of Nigeria. Journal of Applied Sciences 7 (16): 2536-2360, 2007.

[11]. Magbagbeola, N. O. 2001: "The use of Economic Instruments for Industrial pollution Abatementin Nigeria: Application to the Lagos Lagoon". Selected papers, Annual Conferences of theNigerian Economic Society held in Port-Harcourt.

[12]. Orubu, C.O. 2001: "The Contribution of Petroleum to the growth and development of the Nigerian Economy". in M.A. Iyoha and C.E. Okojie (eds.), Essays in Honour of Professor T.M.Yesufu, Department of Economics and Statistics, University of Benin, Forthcoming.

[13]. Orubu, C. O., A. Fajingbesi, A. Odusola and N.O. Magbagbeola. 2002: "Environmental Regulations in the Nigerian Petroleum Industry: Compliance and Implication for Sustainable Development". Research Report, Ibadan, NCEMA/ACBF Collaborative Programme.

[14]. USEPA. 1993; Guide to Environmental Issues, Doc. No 520/B-94-01. United States EnvironmentalProtection Agency, Washington, DC, USA.

[15]. World Bank. 1995: "Defining an Environmental Development Strategy for the Niger Delta", Vol. II, Industry and Energy Operations Division (West Central Africa Department), Washington DC.

[16]. World Health Organisation WHO (2002): “Guidelines for Air Quality” World Health organization,Geneva 